\title{
Tradução e jornalismo em interface: considerações acerca da representação cultural do "11 de Setembro"
}

Silvana Polchlopek

\section{Resumo:}

Este artigo apresenta reflexões em torno de escolhas lexicais empregadas como estratégias de construção de sentido em textos jornalísticos. Tais escolhas são vistas como marcas ou filtros culturais empregados pelo jornalista ao representar um fato para o leitor que compartilha com ele da cultura alvo, mas que desconhece o contexto sócio-cultural onde o fato tem origem. Desta maneira o jornalista é visto como tradutor de fatos, enquanto o conceito de tradução despe-se das amarras do tradicional e expande-se para além do texto, ou seja, para o próprio fato (ZIPSER, 2002). À luz do funcionalismo alemão (NORD, 1991) e do jornalismo articulado como um mapa cultural de sociedades (ESSER, 1998), este artigo explica a tradução e o jornalismo em interface através das contribuições destes teóricos e de exemplos sobre reportagens, traduções paralelas, sobre o "11 de Setembro", publicadas nas revistas Veja e TIME.

\section{Palavras Chave:}

Jornalismo, tradução, representação cultural, 11 de Setembro.

\begin{abstract}
:
This paper presents considerations about lexical choices used as meaning construction strategies in journalistic texts. Such choices are seen as cultural markers or filters used by the journalist to represent a fact to the reader who shares the target culture with him, but who does not know about the socio-cultural context where the fact takes place. Thus, the journalist is seen as a translator of facts, while the concept of translation shifts from the source text to news fact itself (ZIPSER, 2002). Based on the German functionalism (NORD, 1991) and on journalism as a socio-cultural map (ESSER, 1998), this paper demonstrates the interface translation-journalism through these concepts and also through some news reports about the "September 11th", as a parallel corpus, published in Vejaand TIME magazines.
\end{abstract}

\section{Keywords:}

Journalism, translation, cultural representation, September 11th.

Para compreender as reflexões propostas neste artigo é preciso, antes de tudo, estar aberto a pensar o diferente, como diz José Borges Neto (2004: 22) para quem teorias diversas operam abstrações distintas justamente para romper com o senso comum. Isto não é fácil, mas é necessário, de forma que novas reflexões possam ser instauradas sobre nossos objetos de estudo. Isto não significa aceitar o novo e descartar o antigo, mas tão somente 
mostrar que conceitos mais tradicionais, especialmente aqueles voltados à tradução, podem ser ampliados e abrir novos rumos de pesquisas; afinal, ainda citando Borges Neto: "a diversidade teórica é necessária para que uma disciplina se mantenha viva" (2004: 28).

Este esclarecimento se faz necessário porque pensar a tradução como não tendo origem no espaço consagrado de um texto fonte (TF) ou nas comparações entre traduções diretas é, para muitos, uma grande heresia. No entanto, conforme Sobral (2008) a tradução acontece a todo instante sem advir, necessariamente, de um TF. Basta pensar, por exemplo, em diversas situações nas quais temos que explicar novamente uma frase, um parágrafo ou expressar um ponto de vista. Nestes contextos, agimos como tradutores ao tecer escolhas lexicais, sintáticas e estilísticas que tornem possível o entendimento com os outros.

Outro exemplo pode ser o de um grupo de turistas visitando um determinado local pela primeira vez. Para convencê-los de que determinada atração vale a pena ser vista, pois vem de encontro aos interesses do grupo, encomenda-se um texto que descreva seus atrativos. Basta este propósito (skopos) de convencer os turistas para que possamos ter uma tradução que não deriva de um TF (VERMEER, 1986). Assim fundamentados no funcionalismo alemão de Christiane Nord (1991) e no modelo de análise da práxis jornalística proposto por Frank Esser (1998) tecemos considerações acerca da interface tradução-jornalismo e da tradução como a representação cultural de um fato (ZIPSER, 2002). Destes aportes teóricos, apresentamos exemplos retirados das revistas Veja e TIME, representativas do contexto brasileiro e norte-americano, sobre o "11 de Setembro" constituindo, assim, dois olhares distintos sobre um mesmo acontecimento.

\section{O funcionalismo e a pragmática de Nord}

Ser funcionalista em tradução, dentro da perspectiva instaurada por Nord, significa compreender que qualquer texto - traduzido ou não - possui uma função (apelativa, poética, fática, metalinguiística, etc.) articulada por meio do emprego de certas estruturas lingüísticas que servem para concretizar a intenção pragmática do usuário da língua (WEININGER, 2000: 35). Outro aspecto a ser considerado é o fato de que estas funções não se encontram dentro dos limites do texto, mas fora dele, no seu entorno, ou seja, no contexto. Neste sentido, a tradução é entendida por Nord como uma situação comunicativa, intencionada a um destinatário sempre à frente do processo, em prospecção. Isto ocorre porque, segundo a autora, as situações que determinam 'o que' e 'como' as pessoas interagem podem ser modificadas à medida que a comunicação ocorre e que outras variáveis são colocadas em prática, visto que as situações comunicativas não são institucionalizadas ou padronizadas, uma vez inseridas em ambientes culturais que as estabelecem e condicionam (2004: 22). Nestes termos, todo e qualquer texto é uma ação e também a representação de um ato comunicativo que só se concretiza quando, a partir de um canal aberto, os interlocutores constroem sentido(s) para a mensagem, o que só é plenamente possível quando ambos compartilham do mesmo contexto e cooperam a fim de tornar a comunicação algo significativo.

Sendo assim, a proposta de Nord configura-se como uma prática de tradução orientada para a análise do texto, seja traduzido de um TF ou derivado de um propósito específico. A sistematização desta prática pode provocar críticas no sentido de que dificilmente seria aplicável ao dia-a-dia atribulado de um tradutor profissional, o que não se verifica. É preciso deixar claro que este modelo de análise textual se aplica, num primeiro momento, 
ao treinamento de tradutores, propondo uma prática reflexiva mais consciente sobre as inúmeras variáveis a serem gerenciadas no processo tradutório. Tradutores profissionais podem até não empregar o modelo em suas atividades usuais, pois conseguem empregar muitas estratégias quase que intuitivamente; por outro lado, podem se beneficiar destas discussões como forma de aprimorar sua relação com a prática.

Voltando ao modelo, o tradutor deve primeiramente recriar as condições de produção do TF para só então determinar as condições da recepção (leitura) da tradução, em razão de que o propósito do TF pode não ser o mesmo para o TT, ou seja, um texto antes dito científico e elaborado para uma defesa acadêmica pode ser transformado em um artigo para uma revista especializada. O teor pode até ser o mesmo, mas certamente a função persuasiva do primeiro não será mantida no segundo que pode simplesmente ser produzido para informar o leitor sobre as teorias existentes e explorar os resultados práticos da pesquisa. Dentro desta lógica, Nord propõe analisar primeiro os elementos que constituem o contexto situacional do texto ou o que ela chama de Fatores Extratextuais (FE), a saber: emissor, intenção, receptor, meio, lugar, tempo, propósito e a função do texto para os leitores do contexto de partida. Para o leitor atento, tais fatores remetem ao lide clássico no jornalismo e que responde as perguntas: quem, o quê, quando, onde, como e por quê). Eis aí um primeiro paralelo entre tradução e jornalismo estabelecido por Zipser (2002).

Num segundo momento, a análise volta-se aos fatores internos (FI) do texto, ou seja, às estruturas que efetivamente veiculam a mensagem intencionada pelo autor: tema, conteúdo, pressuposições, estruturação, elementos não verbais (fotos, gráficos), léxico, sintaxe, elementos supra-segmentais (aspas, travessões, parênteses, negritos, itálico) e o efeito do texto sobre os leitores. É a união do contexto e dos constituintes lingüísticos que possibilita ao leitor construir sentido(s) para a leitura, ativando todo o seu conhecimento prévio, sua perspectiva de mundo sócio-histórica, seus valores culturais. Já para o tradutor, os FE e os FI representam todo o contexto a ser analisado a partir de um texto escrito ou de uma situação de oralidade antes de efetuar a tradução, com vistas sempre à compreensão do leitor final. Este caminho abre portas para que a tradução comece a se soltar das amarras geralmente impostas pelo $\mathrm{TF}$ direcionando o trabalho para uma tradução fiel à letra ou a forma.

A função textual é estabelecida, portanto, na e pela situação comunicativa. Ainda segundo Nord, a análise do TF deve não só preceder a tradução, como também assegurar ao tradutor total compreensão e interpretação do texto, possibilitando uma base confiável para a tomada de decisões durante o processo tradutório. Conseqüentemente, a tradução é compreendida como uma atividade comunicativa culturalmente marcada. Nord aproximase, assim, das reflexões de Bakhtin sobre enunciados dialógicos e também de Sobral (2008: 50) para quem só é possível depreender sentidos do texto traduzido quando a linguagem é trabalhada especificamente para o destinatário ou grupo de, visto que emprega não somente palavras ou estruturas sintáticas, mas também valores, expectativas, intenções, leituras de outros textos (construídos através da linguagem, verbal ou não), pensamentos, sentimentos. Na tradução, a palavra não é simplesmente, ela é resignificada nessa interação com o Outro.

\section{Instâncias epistemológicas no jornalismo - o modelo de Frank Esser}

Esser é um pesquisador e jornalista alemão, cujo modelo de análise para o jornalismo enfatiza o princípio da interculturalidade. $\mathrm{O}$ autor propõe que o jornalismo seja pensado em 
diversas instâncias ou esferas de atuação que contemplam o jornalismo de fora para dentro, aproximando-se dos FE e FI propostos no modelo de Nord. Estas esferas são variáveis que atuam diretamente sobre o fazer jornalístico, influindo na forma como as notícias são produzidas e recebidas (lidas) por nós. Isto porque a dinâmica destas esferas não é a mesma para o jornalismo, enquanto instituição ou área do conhecimento, em contextos diversos. Elas se modificam e configuram uma identidade específica para o jornalismo de cada país, atuando diretamente sobre o discurso da imprensa, isto é, sobre a forma de narrar as notícias; porém, sem ignorar os princípios epistemológicos que regem esse discurso, tais como objetividade, neutralidade, imparcialidade.

O modelo proposto é chamado de pluriestratificado integrado, visto que são vários os estratos ou camadas que se sobrepõe, moldando o fazer jornalístico e determinando-o como organizador de perfis sociais. Esta é a esfera maior e mais externa - esfera social da mídia - que confere perfis distintos ao jornalismo em contextos distintos. É preciso lembrar que o jornalismo é uma instituição dentro de um todo social maior que, ao mesmo tempo o envolve - ditando notícias para a pauta da redação - e é envolvido por ele - recebendo estas notícias de volta articuladas de tal modo, cuja função maior é informar, mas também formar a opinião do leitor. Esta é a esfera estrutural da mídia que inclui também fatores de mercado (o jornalismo também precisa vender), direito e autocontrole da imprensa, ética da profissão, atuação de sindicatos e a formação do jornalista. A estrutura do jornalismo também responde a uma esfera mais interna, a esfera institucional de organização, isto é, a estrutura interna das redações (redatores, editores chefe) e, por fim, como centro de toda esta organização a esfera subjetiva, ou seja, os valores subjetivos e éticos, além de posicionamentos políticos do próprio jornalista que escreve a matéria.

Recebendo, portanto, a influência de tantas variáveis, Esser compreende o jornalismo como um sistema parcial, isto é, um sistema cujos princípios epistemológicos servem apenas de base para sustentar sua estrutura e legitimar o discurso da imprensa perante a sociedade, mas que não conferem ao jornalismo um padrão único no mundo. Desta maneira, Esser vincula a noção de produção/construção de sentido(s) à noção de cultura, visto que o jornalismo de cada país adquire uma identidade própria, conforme a dinâmica de atuação destas esferas. Da mesma forma, a tradução de um texto qualquer pode receber diferentes versões dependendo do contexto sócio-cultural para o qual se destina.

O trabalho com o conceito de interculturalidade permite, assim, analisar aspectos da prática jornalística internacional como: tradição da imprensa, dinâmica de mercado, ética e formação do jornalista, visto que é a combinação destes fatores que afeta o modo como o jornalismo traduz os acontecimentos em forma de notícias e, como o leitor visualiza e apreende o real através destas traduções ou leituras que a mídia oferece. Zipser (2002: 28) observa que estes fatores interagem de modo semelhante aos fatores externos e internos propostos por Nord (1991) para a tradução e, abrangem a mesma direção - de fora para dentro - ou seja, da sociedade, da situação comunicativa, do fato para o texto escrito; sua influência é recíproca, permeia e condiciona de forma dinâmica toda a prática jornalística. O trabalho de Esser (1998) permite, dessa forma, explicar e justificar o que a autora chama de "diferentes enfoques dados a notícia" quando estas são traduzidas, transmitidas, para outras culturas (ESSER, 1998: 33). Através destas aproximações entre as propostas de Nord e Esser, é possível entender de forma mais clara o que a interface propõe. 


\section{Tradução e Jornalismo em Interface - a representação cultural do fato}

Uma coisa é certa no universo da imprensa: nenhum veículo midiático escreve para si e não há como termos a garantia de que o fato é relatado da forma como realmente aconteceu. $\mathrm{O}$ relato da mídia sempre tem em vista um leitor, assim como na tradução e do fato até a notícia publicada no jornal, revista ou site podemos dizer, pelo que nos expõe Esser, que há um longo caminho percorrido por entre as quatro instâncias já mencionadas. O mesmo vale para o processo tradutório que, tendo em vista o modelo de Nord, apresenta muitas variáveis a serem consideradas, inclusive o público leitor. O que garante, neste caso, que a leitura seja compreendida pelo destinatário com o relato neutro e imparcial do fato são os princípios de objetividade, imparcialidade, entre outros, a imprensa enquanto instituição o que, no caso da tradução, tem a ver com relações de equivalência e fidelidade ao conteúdo do texto, ao autor, por exemplo.

Tais constatações evidenciam, portanto, a existência de interferências entre o fato e o que é publicado na imprensa. Considerando o modelo discutido por Esser, se a imprensa de cada país tem uma identidade específica oriunda de influências do seu entorno social e cultural, pressupomos que um mesmo fato, quando repercute na imprensa por alguma razão, é capaz de gerar diferentes leituras em razão dos diferentes enfoques que recebe. Atuam nesta circunstância o que Traquina (2001); Franzon (2004); Ponte (2005) chamam de valores notícia ou critérios de noticiabilidade, isto é, características específicas que agregam valor ao fato a fim de que se transforme em notícia ou nas palavras de Ponte (2005) intervenções institucionais onde se operam e emergem significados ideológicos. Por esta razão, a leitura que temos sobre um fato não é a única possível. A própria escolha do fato a ser noticiado, bem como a forma como será abordado, refletem padrões sociais e culturais de informação específicos para cada país resultando em diferenças de abordagem para uma mesma notícia.

Neste sentido, se o leitor eventualmente não compartilha do mesmo contexto da cultura de partida em que o fato se origina, o jornalista emprega marcas ou filtros culturais (ZIPSER, 2002), isto é, referentes da cultura alvo, como estratégias de construção de sentido(s) para os textos. Ancorados na cultura alvo, estas marcas não só traduzem como contextualizam o fato, alcançando as funções da imprensa: informar e formar a opinião do leitor, conferindo ao texto uma identidade dominante. Vale lembrar ainda que, segundo Gomes (2000), o que vemos/lemos na imprensa não é o fato em si, o real, mas apenas um efeito de real, ou seja, a representação do fato através das escolhas lingüísticas empregadas para o seu relato. Esta representação, no entanto, não é passiva, como se poderia pensar, mas dinâmica, pois é através dela que o homem constrói o real e que se constitui sujeito histórico e social.

Portanto, o resultado dos paralelos entre Nord e Esser, assim como as marcas culturais e este efeito de real resultam no conceito de tradução como representação cultural, conforme Zipser (2002) - representação porque a notícia apenas esboça o fato e cultural em função dos filtros empregados para aproximar o fato do leitor na cultura alvo. Isto significa que o fato de pertencer a grupos sócio-culturais distintos faz com que a recepção do leitor-final seja um ato condicionado pela sua perspectiva, experiência de mundo e de leitura adquirida e compartilhada no seu meio social: "Trata-se, enfim, de uma leitura e não da leitura desse mesmo fato" (ZIPSER, 2002: 3). Este também é o caminho do tradutor em ambiente funcionalista quando, num primeiro momento, analisa o TF a partir dos seus fatores externos (FE) e internos (FI) para só então partir para a tradução com vistas a um público leitor que pode ser tanto um leitor real (receptor) ou um público idealizado (addressee), 
segundo Nord (1991).

Do encontro destas reflexões, Zipser (2002) estabelece os seguintes pontos:

- O leitor-destinatário está no centro das atividades: jornalística e tradutória. Logo, o texto, seja original ou a tradução, não acaba quando é escrito, pois só concretiza e realiza a sua função no momento da recepção (leitura) pelo destinatário;

- A neutralidade é para o jornalismo o que a transcodificação isenta é para a tradução, ou seja, a desconsideração da linguagem como manifestação de uma cultura e de um processo formador de sentido;

- A interculturalidade é o ponto convergente no contato entre ambientes culturais diversificados através das atividades realizadas pelo jornalista e pelo tradutor;

- A autoconsciência cultural é a dinâmica atuante nas suas tarefas, determinando as diferenças de um em relação ao Outro;

- Tradutor e jornalista são intermediadores culturais, ou seja, a tradução deixa de ser 'transcodificação lingüística', enquanto o jornalista se caracteriza como tradutor dos fatos e,

- A tradutória não se satisfaz quando desvinculada de condicionantes culturais, bem como a prática jornalística não traduz fatos sem referência a cultura local.

Conforme dito no início deste artigo, é bastante difícil, num primeiro momento, pensarmos diferente daquilo a que estamos acostumados, mas enquanto acadêmicos nosso dever é o de, ao menos, estar abertos a possibilidades outras que não apenas as acepções mais tradicionais. Tendo isso em mente, demonstramos a seguir algumas observações sobre a representação cultural em textos paralelos publicados sobre os atentados terroristas de "11 de Setembro" nos contextos brasileiro, representado pela revista Veja, e também no contexto norte-americano, através da TIME.

\section{O “11 de Setembro” - a prática da representação cultural}

O corpus apresentado é um recorte de textos sobre os atentados terroristas no WTC em 2001, publicados pelas revistas Veja [contexto brasileiro] e TIME [contexto internacional] em edição especial. Com um total de 4868 palavras em português e 8540 em inglês, sua seleção obedeceu aos seguintes critérios: i) ambas as revistas são representativas em seus países de origem e detém credibilidade junto aos leitores; ii) estão há mais de 30 anos no mercado editorial representando a história jornalística em seus países de publicação; iii) o fato obteve repercussão mundial na época e, iv) os textos atendem a condição de: autênticos, em contexto de situação real, conforme sugerido por Nord e também as esferas de atuação jornalísticas em Esser. De acordo com tais pressupostos e com a configuração da interface tradução-jornalismo, vejamos primeiro as duas capas da TIME em suas edições: "norte-americana" e "latina".

Um primeiro olhar, mais desatento, diz que não há diferença quanto ao layout de capa (manchete, cores, fotografia). Entretanto, abaixo do logo da TIME, temos um detalhe no subtítulo marcado pelo círculo em vermelho (Fig. 1). Na edição norte-americana este 
subtítulo traz: "America digs out - and digs in" que, grosso modo, poderia significar 'escapar de uma armadilha ou de um problema', enquanto "dig in" se refere a 'cavar uma trincheira, estocar armas e alimento e esperar pela captura do inimigo, não importa o tempo'. Subentende-se para o leitor norte-americano o contexto de uma retaliação que seria inevitável e, como sabemos hoje, desastrosa. A edição para a América Latina traz a mesma expressão, porem com um adendo, o sintagma - "for a war", cuja função é pressupor um leitor que nao compartilha da cultura de origem e, consequentemente, tornar explícito o recado subentendido na primeira edição: "A América supera os problemas e parte para a ação - a guerra(1)". No que diz respeito a esfera social do modelo de Esser (1998), esta estratégia de explicitação garante a objetividade do relato jornalístico e a percepção desta representação do real como verdadeira.

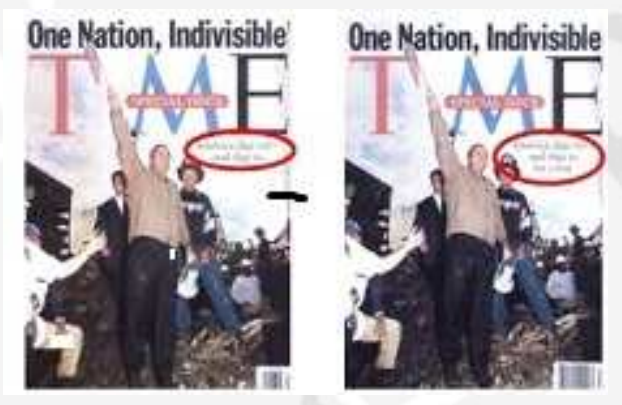

Figura 1: Capas da TIME-edição norte-americana (esquerda) e latino-americana (direita)

Cabe ainda observar a localização da manchete e arriscar uma leitura semiótica: "One Nation, Indivisible", está localizada no topo da capa, preconizando o resultado desta ofensiva e a posição em que os Estados Unidos iriam retomar - o topo, contexto também reforçado pela imagem patriótica do presidente George W. Bush empunhando a bandeira que, apesar de pequena como o país se sentia naquele momento, mostrava-se grande e vitoriosa sobre os escombros nas mãos do seu líder.

Em solo brasileiro, porém, o fato ganha uma outra tradução na Veja, uma outra leitura, mais próxima do público-leitor brasileito que via os Estados Unidos como um império. A manchete de capa estampa: "O Império Vulnerável". O adjetivo chama a atenção porque até então o país era visto como seguro e inatingível, além de evidenciar o tom político e ideológico associado aos norte-americanos (Fig. 2).

A imagem das capas também representa o fato culturalmente, no sentido de apelarem para o emocional dos seus leitores de maneiras distintas: Veja sugere a leitura do "Império" atacado com ousadia, no que era o seu ponto mais forte e culturalmente significativo: o WTC, símbolo do capitalismo para o mundo e, de uma cultura quase personificada para os norte-americanos. Já a TIMEapela para o patriotismo e a união do povo norte-americano. As capas traduzem, portanto, duas perspectivas distintas para um mesmo fato em um processo que não parte, como se observa, de um TF, mas de um fato gerador (ZIPSER, 2002; NORD, 1991; ESSER, 1998). 

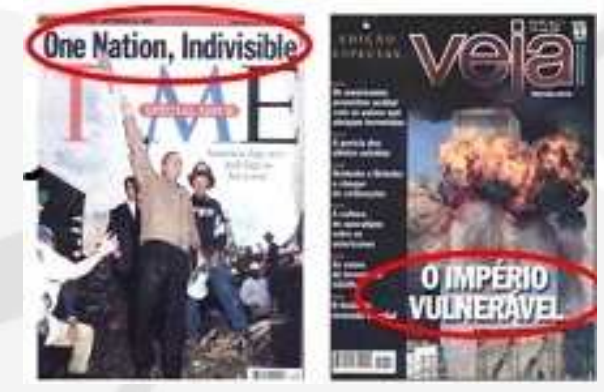

Figura 2: Capas da TIME-edição latino-americana e da revista Veja

Outras evidências da atuação de filtros culturais nas reportagens estão presentes também na temática empregada por Veja e TIME para construir o fato para o coletivo. Os exemplos se referem às três primeiras reportagens publicadas em seqüência na TIME e na Veja.

O primeiro texto da TIME é considerado pela revista um "memorial issue", ou uma edição "in memorium" às vítimas. O título é "Mourning in América" (luto na América) e recria os minutos que se seguiram aos atentados. Sem lide, o texto infiltra-se pelas esferas históricosocial, institucional e subjetiva do modelo de Esser, refletindo o posicionamento direto da editora-chefe Nancy Gibbs, que assina o artigo, empregando pronomes em primeira pessoa. Esta projeção do "eu" narrador produz um efeito de luto coletivo e proximidade com o leitor, de acordo com a função expressiva (SOARES, 2001, p.35), a saber: "What can I do? I've already given blood". Segundo Soares (2001: 46-7) "o próprio repórter torna-se o centro do acontecimento que cobre e, portanto, a melhor fonte de informação". O segundo texto tem como título: "The new breed of terrorist" (a nova geração de terroristas) narrando a trajetória dos pilotos suicidas desde sua chegada aos Estados Unidos até o dia dos atentados. Observe-se que o susbtantivo "breed" pode tanto significar "geração" quanto "raça de animais". Fica a cargo do leitor a interpretação: geração implica terroristas suicidas que morrem em nome de sua religião, enquanto "raça" implica considerá-los como sendo animais, em virtude de atitudes que podem ser tidas pelo leitor como irracionais. A terceira e última reportagem apresenta um personagem até então desconhecido do público e da mídia: Osama bin Laden ou "The Most Wanted Man In The World", acordo com o título da TIME. Uma possível leitura nos remete à origem texana do ex-presidente Bush. No velho oeste, o Texas era cenário de tiroteios, perseguições e cartazes para a captura dos bandidos com o famoso "Wanted" (procurado), a foto do bandido e o valor da recompensa logo abaixo. O mesmo ocorre na reportagem: o lide explicita o valor "He lives a life fired by fury and faith. Why terror's $\$ 250$ million man loathes the U.S." e a foto transmite a frieza do terorista tingida de vermelho.

Em Veja, o primeiro texto tem como título "A Descoberta Da Vulnerabilidade" e um relato cujo tom político e ideológico se torna claro logo no início. Destaque para o verbo 'descobrir' que remete a algo antes desconhecido ou que não se queria enxergar. O segundo focaliza o desabamento das torres sob o título "A Morte no Fogo, num Salto ou no Desabamento". Estão presentes neste relato valores notícia como: inesperado; tragédia; drama; raridade e conflito expressos por uma pergunta retórica respondida no lide: "Como os pilotos suicidas conseguiram destruir as torres feitas para resistir a colisões, incêndios tremores? Juntaram tudo isso num atentado". Além de descrever o desespero de pessoas que não tinham para onde escapar, visto que acabariam morrendo de algum modo, esta segunda reportagem remete à primeira em que se descobre que as torres de aço não eram 
mais inatingíveis. Uma marca cultural explícita incide sobre a comparação tecida entre o fogo nas torres gêmeas e o incêndio no Edifício Joelma, em São Paulo no ano de 1976. O jornalista-tradutor faz uso deste evento para ancorar o referente de modo a fazer com que o leitor consiga compreender a magnitude do incêndio no WTC.

O último texto também apresenta bin Laden como o "O Inimigo Número 1 da América", uma alusão às histórias do Batman, cujo inimigo, o Curinga, é referido de maneira igual. Os filtros culturais atuam ainda no item pressuposições, integrante dos fatores externos da abordagem de Nord. Esta análise envolve estratégias de expansão ou omissão de informações empregadas tanto na tradução quando na produção textual jornalística. Nos textos da TIME, as pressuposições referem-se a três grandes grupos:

- Estados Unidos: valores americanos, seriados da TV americana nos quais as torres aparecem no cenário (Sex and the City, Wall Street, Working Girl, The Sopranos), a cidade de Manhattan para compreender a localização dos prédios, hinos religiosos americanos; procedimentos de embarque nos aeroportos americanos, a cidade da Florida, atentados ao WTC em 93;

- Guerras: genocídio nazista, guerra do Kuwait e Somália;

- Afeganistão: conhecer a posição geográfica do Afeganistão invasão dos Afegãos à antiga URSS, as cidades de Meca e Medina.

Já os textos da Veja pressupõe quatro grupos principais referentes à:

- Guerra: Guerra fria, do Afeganistão, Saddam Hussein e Kuwait, Aiatolá Khomeini.

- Americanos: Ataque terrorista ao WTC em 93, Timothy McVeigh(2) o assassino de Oklahoma, ataque japonês a Pearl Harbor, bombas atômicas de Hiroshima e Nagasaki.

- Atentados terroristas: Chacinas em Roma e Viena em 85.

- Leitores brasileiros: incêndio no edifício Joelma em São Paulo e ter viajado alguma vez de avião.

Pressupor informações permite ao leitor atribuir sentido ao texto e estabelecer uma ponte entre o seu conhecimento prévio e o conhecimento novo adquirido através da leitura; por esta razao, as pressuposições devem bem pensadas por tradutores e jornalistas, a fim de fazer com o texto final funcione, ou seja, cumpra com sua função, seja ela qual for. Do cntrário, o texto torna-se fragmentado, exigindo deste leitor uma capacidade de contextualização que nem sempre apreende todos os sentidos do texto.

Um último item que vale a pena mencionar é o léxico, também parte dos fatores internos em Nord. O léxico é uma das maneiras de demonstrarmos a construção lingüística textual, por exemplo: as cadeias isotópicas podem refletir a Intenção (fator externo) do produtor textual através da seleção de palavras e revelar também o Efeito intencionado sobre o Receptor.

Em relação a TIME, a função do léxico é corresponder às expectativas dos leitores que 
esperam encontrar na revista o "to know why" (o por quê) dos atentados; portanto, as escolhas tendem a estabelecer um pólo do 'bem contra o mal', isto é, o mundo civilizado (Estados Unidos e países aliados) contra as nações bárbaras (países árabes muçulmanos). Porém, esta mesma leitura no âmbito da América Latina(3) pode ter um efeito contrário, visto que, a nação norte-americana não é uma unanimidade neste contexto, além de não azer parte da cultura brasileiro o culto aos heróis, como induz o já conhecido patriotismo norte-americano. Neste sentido, a seleção lexical da TIME objetiva construir a imagem de um país atacado em seu ponto vital e sem direito a defesa, justificando a retaliação apregoada nas capas das duas edições da revista.

As escolhas de Veja, por outro lado, são como já dissemos, assumidamente políticoideológicas através do uso constante de adjetivos avaliativos em favor dos norte-americanos reforçando, entre os leitores brasileiros, os valores daquele país. Veja faz ainda uma generalização perigosa ao afirmar que "todo árabe é saudita" e que "o uso do turbante caracteriza o terrorista". Aqui o filtro cultural do jornalista-tradutor deveria ter buscado a informação de que o turbante é um traje de utilidade prática (protege contra o sol) associado cultural, e não dogmaticamente, à religião muçulmana. Povos da região do Punjab, noroeste da Índia, usam o turbante e não são, necessariamente, islamitas ou terroristas. Portanto, sendo o léxico também revelador de traços culturais, agrupamos os temas principais sobre os quais se constrói a rede semântica do corpus:

\section{Rede semântica no corpus da TIME:}

- EUA: vices; luck; freedom; gifts;

-WTC: a teeth pulled; great brothers of New York; lodestars; local mountains;

- Atentados: Terror; airplanes into missiles; unthinkable;

- Terroristas: Our enemies; the killers who hate us; suicide bombers; zealots.

\section{Rede semântica no corpus da Veja:}

• EUA: Vulnerabilidade; império; superpotência; nação mais poderosa do planeta;

-WTC: Ícones; identidade nacional; supremacia econômica; coração do poder;

- Bin Laden: responsável pelo atentado; principal suspeito; milionário saudita.

- Atentados: ofensiva; larga escala, sem similar; atrocidades; agressão; horror; destruição; cenário de morte; operação de magnitude; ato de vingança; insano;

- Terroristas: fanáticos; seqüestradores; milícia fundamentalista; covardes; minoria radical; disposição para matar e morrer; ódio; sangue; são todos árabes, turma do turbante.

Percebe-se que Veja incita o que se poderia entender como preconceito ou atitude antisemita em relação ao povo árabe. Por razões de espaço, não nos detemos em análises mais pontuais, mas o que temos é suficiente para contextualizar o uso de marcadores culturais no 
texto jornalístico que, não só traduzem o fato para os leitores, como também aproximam o referente do leitor no seu contexto de chegada.

\section{Considerações finais}

O que se percebe é que, de fato, temos acesso a apenas uma das inúmeras leituras possíveis para um mesmo acontecimento e nisto não há novidade. O novo incide na maneira de detectar e compreender estas estratégias, enquanto leitores, visto que as marcas nos oferecem a dimensão cultural tanto do jornalismo quanto da tradução, estimulam a percepção do real como parte da cultura destinatária e garantem ao público a identificação, compreensão e contextualização do fato de forma a permitir que se construa sentido a partir dele. E isso só é possível se a prática for capaz de sistematizar o que a sociedade é e como ela funciona, conforme demonstrado pelas reflexões de Nord e Esser. O terrorismo é assim culturalmente representado, ou seja, culturalmente traduzido, em razão de as marcas culturais utilizadas por Veja e TIME, em seus respectivos contextos, construírem uma cultura partilhada (regional, nacional, de interesses de um grupo) e, logicamente, uma memória coletiva para o social.

A visão ampliada de texto e a tradução como representação cultural (ZIPSER, 2002) são, portanto, conceitos plenamente viáveis que, ancorados na cultura condicionam a escrita e a leitura dos textos. Tal constatação deve fazer com que repensemos nosso papel como leitores, no sentido de não agir passivamente perante o que nos é apresentado. O mesmo vale para o processo tradutório, cujo produto final jamais é o mesmo, podendo gerar tantas traduções quando forem os profissionais dispostos ao desafio de uma retextualização. Para finalizar, lembramos mais uma vez que uma nova teoria não tem por objetivo se mostrar como a verdade absoluta, mas sim abrir caminhos para se pensar um determinado objeto com outros olhos e é isto que acreditamos ser o papel e o perfil de um pesquisador: instigar pensamentos diferentes e estar aberto a novas possibilidades, o que é representativo da proposta deste artigo - pensar jornalismo e a tradução partindo de perspectivas distintas, mas mutuamente complementares e enriquecedoras.

\section{Bibliografia:}

ESSER, Frank. Die Kräfte hinter den Schlagzeilen - Englischer und deutscher Journalismus im Vergleich. München/Freiburg, Verlag Karl Arber, 1998.

FRANZON, Erica. Os valores-notícia em telejornais. Monografia apresentada ao Programa de Pós-Graduação em Jornalismo e Mídia da Universidade Federal de Santa Catarina, 2004.

GOMES, Mayra Rodrigues. Jornalismo e Ciências da Linguagem. São Paulo: Hacker Editores, Edusp, 2000.

BORGES NETO, J. Ensaios de Filosofia da Lingüística. São Paulo: Parábola, 2004.

NORD, Christiane. Text Analysis in Translation. Amsterdan, Atlanta, GA, Rodopi. Tradução de Christiane Nord e Penelope Sparrow, 1991.

"O Império Vulnerável”. Veja. São Paulo, Editora Abril, Edição Especial: n³7, 19 de 
Setembro de 2001

"One Nation, Indivisible". TIME Magazine. Latin America Edition - Time Inc. International, Hollywood-FL, Special Edition: $n^{\circ}$ 11, v.158, September 24th, 2001.

PONTE, Cristina. Para entender as notícias: linhas de análise do discurso jornalístico. Florianópolis: Insular, 2005.

SOARES, Rosana de Lima. Imagens Veladas: AIDS, imprensa e linguagem. São Paulo: Annablume, 2001.

SOBRAL, Adail. Dizer o mesmo aos outros: ensaios sobre tradução. São Paulo: Special Book Services Livraria, 2008.

TRAQUINA, Nelson. O estudo do Jornalismo no séc. XX. RS: Unisinos, 2001.

WEININGER, Markus. A Verbalklammer: estruturas verbais descontínuas em alemão. Tese apresentada ao Departamento de Letras Estrangeiras Modernas da Universidade Federal de Santa Catarina, UFSC, 2000.

ZIPSER, Meta Elisabeth. Do fato a reportagem: as diferenças de enfoque e a tradução como representação cultural. Tese (doutorado em língua e literatura alemã)- Departamento de Letras Modernas da Faculdade de Filosofia, Letras e Ciências Humanas da Universidade de São Paulo, USP, 2002.

\section{Notas:}

(1) Sugestão de tradução da autora para "America digs out and digs in - for a war".

(2) Considerado pelos Estados Unidos um terrorista doméstico, McVeigh explodiu uma biblioteca em Oklahoma em 1985, causando milhares de mortos e vitimas. Foi considerado o maior ataque terrorista da história dos Estados Unidos até o "11 de Setembro". McVeigh foi movido pela religião, e considera-se um vingador e um herói. Disponível em: http://www.crimelibrary.com/serial_killers/notorious/mcveigh/dawning_1.html. Acessado em: Maio/2009.

(3) Os textos das edições americanas e brasileira são iguais em conteúdo e layout.

\section{Mini Currículo :}

Silvana Polchlopek é doutoranda do Programa de Pós Graduação em Estudos da Tradução da Universidade Federal de Santa Catarina (UFSC). 